\title{
23-Gauge Pars Plana Vitrectomy Alone by a Bimanual Technique for the Removal of Dense Posteriorly Dislocated Crystalline Lens
}

\author{
Bingwen Lu' ${ }^{1}$ Xingwei Wu², Qinghua Qiu2* \\ ${ }^{1}$ Ophthalmology Department, Seventh People's Hospital of Shanghai University of TCM, Shanghai, China \\ ${ }^{2}$ Ophthalmology Department, Shanghai General Hospital, Shanghai, China \\ Email: 704487389@qq.com
}

How to cite this paper: Lu, B.W., Wu, X.W. and Qiu, Q.H. (2016) 23-Gauge Pars Plana Vitrectomy Alone by a Bimanual Technique for the Removal of Dense Posteriorly Dislocated Crystalline Lens. Open Journal of Ophthalmology, 6, 228-239.

http://dx.doi.org/10.4236/ojoph.2016.64032

Received: November 2, 2016

Accepted: November 13, 2016

Published: November 16, 2016

Copyright $\odot 2016$ by authors and Scientific Research Publishing Inc. This work is licensed under the Creative Commons Attribution International License (CC BY 4.0).

http://creativecommons.org/licenses/by/4.0/

\begin{abstract}
Background: We sought to verify the efficacy and safety of transconjunctival 23gauge pars plana vitrectomy (PPV) alone by our bimanual technique for the removal of dense posteriorly dislocated crystalline lens. Methods: A retrospective, noncomparative, interventional study of 31 consecutive cases of patients who underwent 23-gauge PPV alone for the removal of dense posteriorly dislocated crystalline lens following complicated cataract surgeries using our bimanual technique was conducted. The main outcomes measured included best-corrected visual acuity (BCVA), preoperative intraocular pressure (IOP), postoperative IOP and postoperative complications. Results: In all 31 cases included in this study, those dense posteriorly dislocated crystalline lenses were successfully removed. The enrolled patients consisted of 17 males and 14 females with a mean age of $(75.84 \pm 6.17)$ years (range $59-90)$. The mean follow-up length was $(7.61 \pm 1.87)$ months with a range of 6 months to 1 year. The mean preoperative BCVA was $0.22 \pm 0.11 \log$ MAR system, and the postoperative BCVA was $0.33 \pm 0.07 \log$ MAR system after 6 months of follow-up. The mean operative time was $46.32 \pm 4.80$ minutes with a range of 38.00 to $57.00 \mathrm{mi}-$ nutes. All of the conjunctival incisions self-closed within the first week with no wound leakage or hemorrhage. The postoperative complications were relatively rare. Conclusions: The removal of dense posteriorly dislocated crystalline lens might be a challenge for micro-incision vitrectomy. Our bimanual technique was proved to be an effective and safe method for those particular dense lenses using 23-gauge alone.
\end{abstract}

\section{Keywords}

23-Gauge Pars Plana Vitrectomy, Dense Posteriorly Dislocated Crystalline Lens, Bimanual Technique, Stop-and-Chop, Divide-and-Conquer 


\section{Introduction}

Despite continuing improvements in phacoemulsification machines and the development of new surgical techniques, posteriorly dislocated crystalline lens remains a welldocumented complication of modern cataract surgery that occurs with rates ranging from $0.3 \%$ to $1.1 \%$ [1].

There are many techniques for moving posteriorly dislocated crystalline lenses. The standard 20-gauge vitrectomy system has been traditionally applied [2] [3]. The introduction of micro-incision vitrectomy surgeries in the early to mid-2000s enabled the effective management of posteriorly dislocated crystalline lenses with 23- or 25-gauge systems [4]-[10]. However, cases with dense lens material remain challenging for the smaller 23- and 25-gauge systems. One sclerotomy is commonly enlarged by the majority of surgeons to allow for the use of a 20-gauge fragmatome [11]. Such procedure requires a conjunctival peritomy, a larger sclerotomy, and closure of the wounds with sutures, which may lead to increased operative and healing times, postoperative discomfort and refractive changes [2] [3].

Herein, we describe a bimanual technique for the removal of particular dense posteriorly dislocated crystalline lenses that involves only a 23 -gauge vitrectomy which uses the light pipe as a prechopper and incorporates the "stop-and-chop" as well as the "divide-and-conquer" techniques of traditional cataract surgery.

\section{Patients and Methods}

\subsection{Study Design and Subjects}

This was a retrospective, non-comparative, interventional case series study of consecutive patients who underwent 23-gauge PPV alone via our bimanual technique for the removal of dense posteriorly dislocated crystalline lenses between April 2012 and January 2015. All of the surgeries were performed by one of the authors (Q.-H.Q). Patients with $<6$ months of postoperative follow-up were excluded from the study. Informed consent was obtained from all subjects prior to the surgeries. The study was approved by the Ethics Committee of Shanghai General Hospital, where the study took place.

\subsection{Examination Protocol}

Preoperative, intraoperative and postoperative patient data were retrospectively evaluated from the medical records and included demographic information, previous ocular history, BCVA as measured with logMAR system, slit lamp biomicroscopy, IOP as measured with noncontact tonometry (Nikon, Japan), posterior segment visualization via indirect ophthalmoscopy, duration of PPV and complications. The gradings of the nuclear densities were performed preoperatively by the operating surgeon according to LOCS II. Only patients with N3 nuclear densities were included in the study. The presence of brunescent nuclear pieces was considered. In all cases, the amount of dislocated nuclear material was also intraoperatively graded by the operating surgeon. Postoperative ocular hypertension was defined as an IOP equal to or greater than $30 \mathrm{mmHg}$, and hypotonia was defined as an IOP equal to or below $5 \mathrm{mmHg}$. 


\subsection{Surgical Procedures}

All surgical procedures were performed by the same vitreoretinal surgeon (Q.-H.Q) using a standard three-port, transconjunctival 23-gauge PPV system (Bausch \& Lomb, St. Louis, MO, USA). In cases of same-day PPV, a single 10-0 nylon suture was placed on the corneal tunnel prior to trocar insertion to prevent wound leakage. Full vitrectomies were performed with the aid of sclera depression in all cases. After the vitrectomies were completed, the dense posteriorly dislocated crystalline lenses were removed with the 23-gauge PPV system alone in all cases.

Lensectomy with a cutter was attempted using modified settings. The standard vitrectomy settings typically include a maximum proportional aspiration vacuum of 300 $400 \mathrm{mmHg}$ and a fixed cut rate of $300-600 \mathrm{cpm}$. To facilitate the removal of those particular dense lens fragments during lensectomy, the "3D mode" was used (start treadle $2500 \mathrm{cpm} / 150 \mathrm{mmHg}$, full treadle $300-600 \mathrm{cpm} / 300-400 \mathrm{mmHg}$ ). The infusion pressure for the initial vitrectomy was set to $26 \mathrm{mmHg}$ using an IOP compensation system and increased to $35 \mathrm{mmHg}$ (also with IOP compensation) for the lensectomy.

Articulate descriptions of the surgical technique were illustrated by the presented figures (Figures 1-4).

Firstly, the 23-gauge vitreous cutter was used to capture the posteriorly dislocated crystalline lens with illumination provided by the light pipe (Figure 1). Complete crystalline lenses or large crystalline lens fragments were somehow difficult to grasp, or easy to fall off when captured, thus, an increased maximum aspiration vacuum was required to help grasp the posteriorly dislocated lens material in this procedure (the aspiration vacuum was increased to $600 \mathrm{mmHg}$, and the cut rate was reduced to $300 \mathrm{cpm}$ from $600 \mathrm{cpm}$ when vitrectomy).

Secondly, the lens material was rotated upside down with the guidance of the 23-gauge vitreous cutter and the light pipe as an assistance (Figure 2). The complete crystalline lenses or crystalline lens fragments tended to trip off the vitreous cutter. It was important for the vitreous cutter to clung to the central point on the front surface of the lens material, and for the operator to increase the aspiration vacuum. Thus, the lens material could be rotated upside down and well stabilized by the suction, the weight of the lens material itself as well as the support of the vitreous cutter. The 23-gauge vitreous cutter was then placed downward.

Subsequently, the light pipe was used as a prechopper and the "stop-and-chop" surgical technique was applied to chop the lens material into two parts (Figure 3 ). The pressure must be on the central point of the lens material.

The "divide-and-conquer" technique was then repetitively applied to chop the lens material into smaller parts until the parts could be guided by the light pipe into the vitreous cutter part (Figure 4).

To safely remove the lens fragments from the vitreous cavity, the lens materials were aspirated with the cutter and carried away from the retinal surface into the middle of the vitreous cavity. In all cases, at the end of the PPV procedure, the peripheral retina was thoroughly examined for any iatrogenic retinal breaks. The patients included in 
this study underwent PPV and intraocular lens (IOL) implantation either in the same surgical setting or in settings other than those of the complicated cataract surgeries. The sclerotomy ports were then removed, and the wounds were examined for any leaks that were sutured when present with 8-0 absorbable suture.

\subsection{Main Outcome Measures}

All patients were examined on postoperative day 1 and at various later times until at least 6 months postoperatively depending on the patients' recovery.

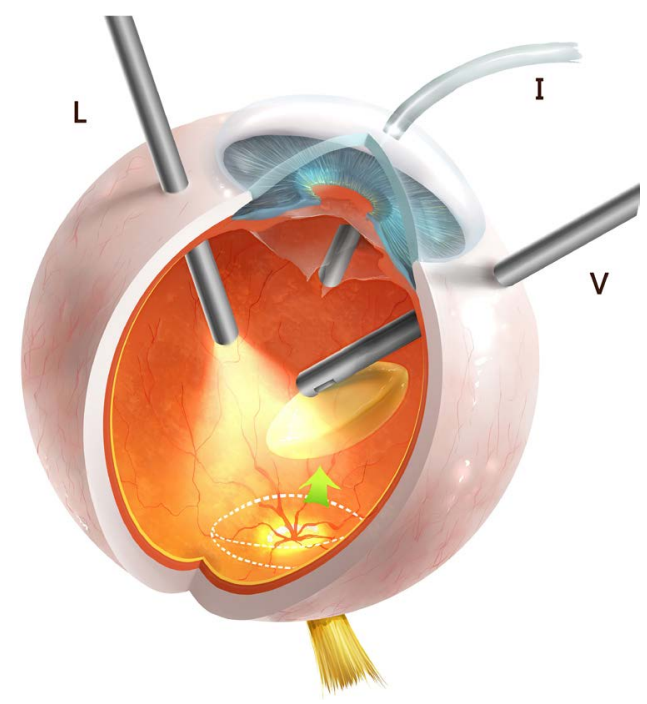

I: infusion; L: light pipe; V: vitreous cutter

Figure 1 . The posteriorly dislocated crystalline lens was captured by the 23gauge vitreous cutter with the help of the light pipe.

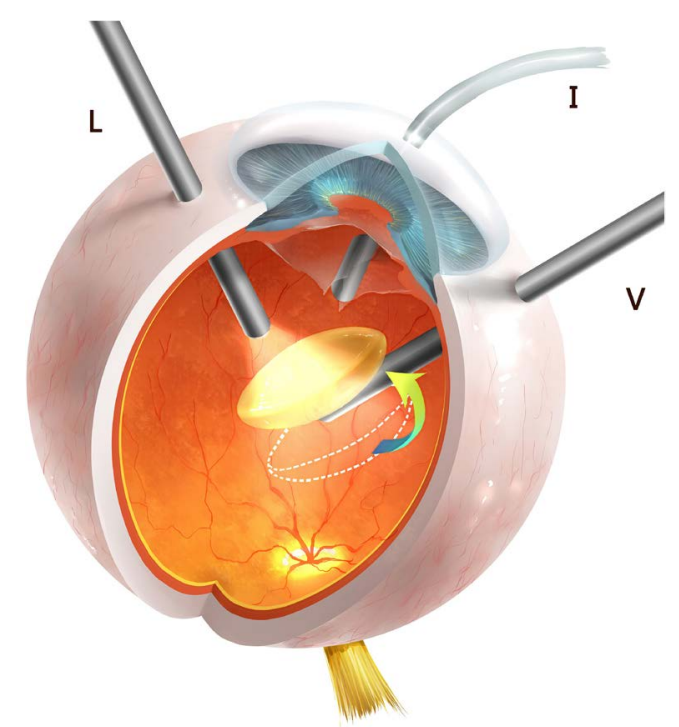

I: infusion; L: light pipe; V: vitreous cutter

Figure 2. The lens material was rotated upside down with the guidance of the 23-gauge vitreous cutter that clung to its central point on the front surface. 


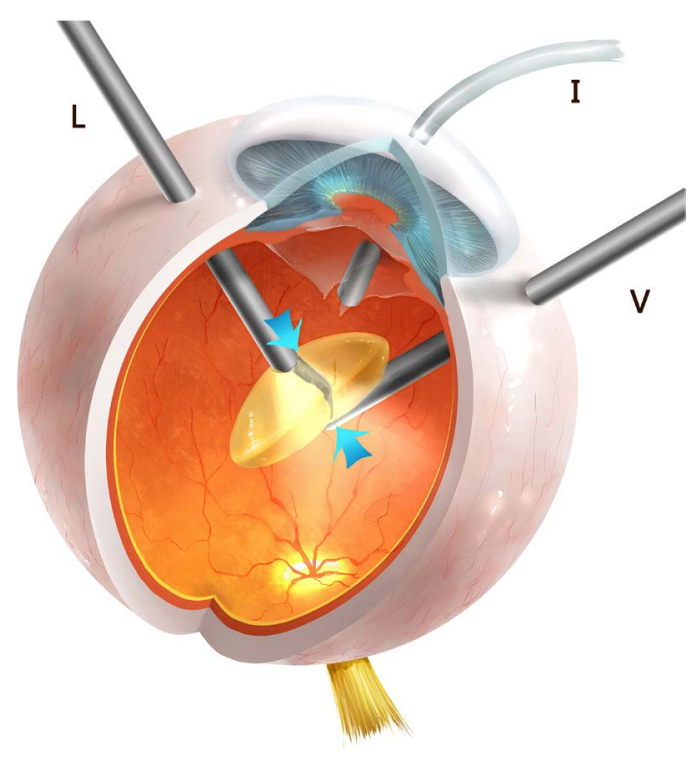

I: infusion; L: light pipe; V: vitreous cutter

Figure 3. The light pipe was used as a prechopper via the application of pressure on the top of the central point of the lens material to chop it into two parts.

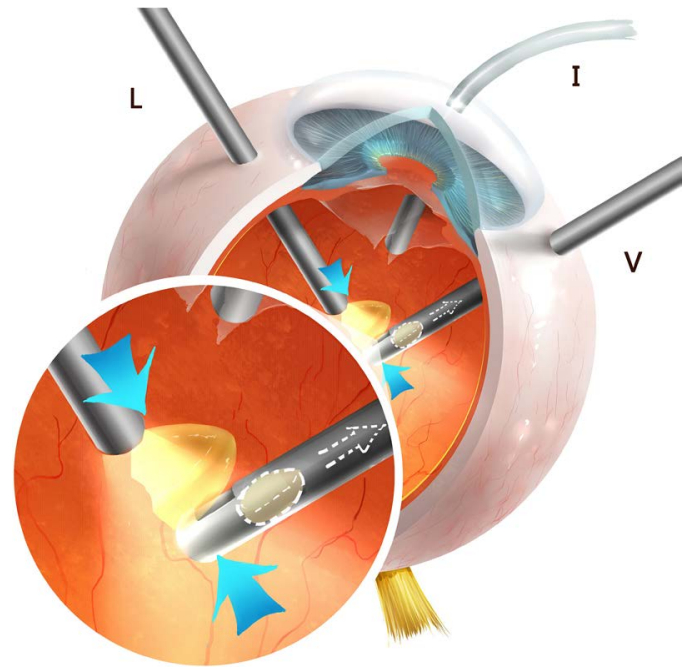

I: infusion; L: light pipe; V: vitreous cutter

Figure 4. The lens material was chopped into smaller parts until the parts could be guided by the light pipe into the vitreous cutter part.

The patients were monitored for complications, including wound leakage, hemorrhage, retinal tears or detachments, hypotonia, glaucoma, endophthalmitis, choroidal detachment and cystoid macular edema (CME).

\subsection{Statistical Analysis}

The continuous variables are described as the means \pm standard deviations, and the categorical variables are described as percentages. Comparisons of means were performed with two-tailed $t$ tests. $\mathrm{P}<0.05$ was considered significant. 


\section{Results}

\subsection{Demographical Results}

Thirty eyes of 31 patients who underwent 23-gauge PPV alone for the removal of dense posteriorly dislocated crystalline lenses and had a minimum of 6 months postoperative follow-up were included in the study. The enrolled patients consisted of 17 males and 14 females with a mean age of $(75.84 \pm 6.17)$ years (range $59-90)$. The mean amount of dislocated nuclear material as a percentage of the whole lens was $87.42 \% \pm 12.10 \%$ (range $60 \%-100 \%$ ). None of the patients exhibited dislocation of the brunescent nuclear fragments (Table 1).

\subsection{Visual Outcomes}

The mean length of follow-up was $7.61 \pm 1.87$ with a range of 6 months to 1 year.

Prior to cataract surgery, the mean BCVA was $0.22 \pm 0.11 \log$ MAR system, and the mean BCVA improved to $0.33 \pm 0.07 \operatorname{logMAR}$ system following the surgeries. The visual outcomes of the patients significantly improved following surgery $(\mathrm{t}=5.13 ; \mathrm{P}<$ 0.01; Table 1 and Table 2).

\subsection{Surgical Procedures}

All patients underwent 23-gauge PPV alone without the enlargement of any sclerotomies.

PPV was performed on the same day immediately after complicated cataract extraction in 29 cases, and 2 patients underwent PPV 7 and 8 day later. The mean operative time was $46.32 \pm 4.80$ minutes with a range of 38.00 to 57.00 minutes.

In 22 cases (70.97\%), dense nuclear pieces obstructed the vitreous cutter, which was unblocked via the manual injection of a balanced salt solution into the cutter (Table 2 and Table 3).

\subsection{Intraocular Pressure Changes}

Prior to PPV, the mean IOP was $16.32 \pm 2.06 \mathrm{mmHg}$. Only one patient $(3.23 \%)$ had an IOP $>21 \mathrm{mmHg}$, and this condition was the result of a history of POAG. On postoperative day 1 , the mean postoperative IOP was $16.90 \pm 3.99 \mathrm{mmHg}$, and there were no cases of ocular hypotonia. Only one patient (3.23\%) exhibited a postoperative IOP greater than $30 \mathrm{mmHg}$ on the first postoperative day (Table 1 and Table 2).

\subsection{Intraoperative and Operative Complications}

In 22 cases (70.97\%), dense nuclear pieces obstructed the vitreous cutter, but these obstructions were easily removed via the manual injection of a balanced salt solution into the cutter.

All of the conjunctival incisions self-closed within the first week of follow-up. No granulation was observed in the conjunctiva. Seven patients $(22.58 \%)$ presented with corneal edema on the first postoperative day, but these conditions all resolved by the 1-week postoperative visit. 
Table 1. Demographics, preoperative and intraoperative clinical characteristics.

\begin{tabular}{|c|c|c|c|c|c|c|c|}
\hline Patient & $\begin{array}{l}\text { Age, } \\
\text { years }\end{array}$ & Sex & $\begin{array}{c}\text { Preexisting } \\
\text { ocular } \\
\text { disease }\end{array}$ & $\begin{array}{c}\text { Grade of } \\
\text { nucleus } \\
\text { density }\end{array}$ & $\begin{array}{c}\text { Preop.VA, } \\
\text { logMAR }\end{array}$ & $\begin{array}{l}\text { IOP } \\
\text { before } \\
\text { PPV }\end{array}$ & $\begin{array}{l}\text { Days } \\
\text { to } \\
\text { PPV }\end{array}$ \\
\hline 1 & 72 & M & None & N 3 & 0.1 & 14 & 0 \\
\hline 2 & 66 & M & None & N 3 & 0.2 & 16 & 0 \\
\hline 3 & 78 & F & POAG & N 3 & 0.1 & 22 & 0 \\
\hline 4 & 69 & M & None & N 3 & 0.3 & 14 & 7 \\
\hline 5 & 76 & F & None & N 3 & 0.3 & 16 & 0 \\
\hline 6 & 82 & M & NPDR & N 3 & 0.1 & 18 & 0 \\
\hline 7 & 73 & F & None & N 3 & 0.2 & 15 & 0 \\
\hline 8 & 67 & F & None & N 3 & 0.4 & 14 & 0 \\
\hline 9 & 59 & $\mathrm{M}$ & None & N 3 & 0.4 & 18 & 8 \\
\hline 10 & 81 & $\mathrm{M}$ & None & $\mathrm{N} 3$ & 0.1 & 18 & 0 \\
\hline 11 & 78 & $\mathrm{M}$ & None & N 3 & 0.1 & 17 & 0 \\
\hline 12 & 73 & F & None & N 3 & 0.2 & 14 & 0 \\
\hline 13 & 81 & F & None & N 3 & 0.2 & 13 & 0 \\
\hline 14 & 77 & $\mathrm{~F}$ & None & N 3 & 0.2 & 16 & 0 \\
\hline 15 & 84 & $\mathrm{M}$ & None & N 3 & 0.1 & 17 & 0 \\
\hline 16 & 77 & $\mathrm{M}$ & NPDR & N 3 & 0.2 & 19 & 0 \\
\hline 17 & 75 & F & None & N 3 & 0.2 & 16 & 0 \\
\hline 18 & 82 & M & None & N 3 & 0.1 & 16 & 0 \\
\hline 19 & 75 & F & None & N 3 & 0.2 & 17 & 0 \\
\hline 20 & 78 & M & POAG & N 3 & 0.2 & 20 & 0 \\
\hline 21 & 82 & M & Dry AMD & N 3 & 0.1 & 15 & 0 \\
\hline 22 & 90 & M & None & N 3 & 0.1 & 16 & 0 \\
\hline 23 & 81 & F & None & N 3 & 0.2 & 17 & 0 \\
\hline 24 & 76 & F & None & N 3 & 0.2 & 13 & 0 \\
\hline 25 & 81 & M & None & N 3 & 0.2 & 16 & 0 \\
\hline 26 & 78 & M & None & N 3 & 0.3 & 18 & 0 \\
\hline 27 & 75 & F & None & N 3 & 0.3 & 15 & 0 \\
\hline 28 & 73 & F & Dry AMD & N 3 & 0.2 & 14 & 0 \\
\hline 29 & 71 & M & None & N 3 & 0.4 & 18 & 0 \\
\hline 30 & 69 & M & None & N 3 & 0.4 & 16 & 0 \\
\hline 31 & 72 & F & None & N 3 & 0.5 & 18 & 0 \\
\hline
\end{tabular}

None of the patients retained lens fragments postoperatively. There were no cases of postoperative retinal detachment. Postoperative CME developed in 2 patients (6.45\%) 
and was treated with topical steroid and non-steroid drops with resolution of the intraretinal fluid. Only a single patient (3.23\%) exhibited a postoperative IOP greater than $30 \mathrm{mmHg}$ on the first postoperative day, and this condition was successfully topically

Table 2. Postoperative clinical characteristics.

\begin{tabular}{|c|c|c|c|c|}
\hline Patient & $\begin{array}{l}\text { Amount of dislocated } \\
\text { nuclear matirial, } \%\end{array}$ & $\begin{array}{l}\text { PPV duration, } \\
\text { min }\end{array}$ & $\begin{array}{c}\text { Postoperative IOP } \\
\text { (day 1) }\end{array}$ & $\begin{array}{l}\text { Final VA, } \\
\text { logMAR }\end{array}$ \\
\hline 1 & 80 & 46 & 17 & 0.3 \\
\hline 2 & 100 & 52 & 17 & 0.4 \\
\hline 3 & 80 & 47 & 35 & 0.3 \\
\hline 4 & 80 & 50 & 15 & 0.4 \\
\hline 5 & 100 & 48 & 14 & 0.4 \\
\hline 6 & 80 & 43 & 19 & 0.2 \\
\hline 7 & 100 & 43 & 15 & 0.3 \\
\hline 8 & 70 & 42 & 14 & 0.4 \\
\hline 9 & 90 & 45 & 16 & 0.4 \\
\hline 10 & 100 & 43 & 20 & 0.4 \\
\hline 11 & 80 & 45 & 17 & 0.3 \\
\hline 12 & 90 & 52 & 15 & 0.3 \\
\hline 13 & 100 & 52 & 14 & 0.2 \\
\hline 14 & 100 & 40 & 14 & 0.4 \\
\hline 15 & 100 & 53 & 15 & 0.2 \\
\hline 16 & 90 & 57 & 18 & 0.3 \\
\hline 17 & 80 & 50 & 17 & 0.3 \\
\hline 18 & 60 & 42 & 16 & 0.2 \\
\hline 19 & 100 & 47 & 16 & 0.4 \\
\hline 20 & 70 & 52 & 22 & 0.3 \\
\hline 21 & 90 & 51 & 15 & 0.3 \\
\hline 22 & 80 & 40 & 17 & 0.2 \\
\hline 23 & 100 & 38 & 18 & 0.3 \\
\hline 24 & 70 & 42 & 14 & 0.4 \\
\hline 25 & 80 & 45 & 15 & 0.3 \\
\hline 26 & 100 & 48 & 18 & 0.4 \\
\hline 27 & 100 & 50 & 13 & 0.4 \\
\hline 28 & 100 & 45 & 14 & 0.3 \\
\hline 29 & 80 & 42 & 19 & 0.4 \\
\hline 30 & 90 & 38 & 15 & 0.4 \\
\hline 31 & 70 & 48 & 20 & 0.4 \\
\hline
\end{tabular}


Table 3. Intraoperative and postoperative complications.

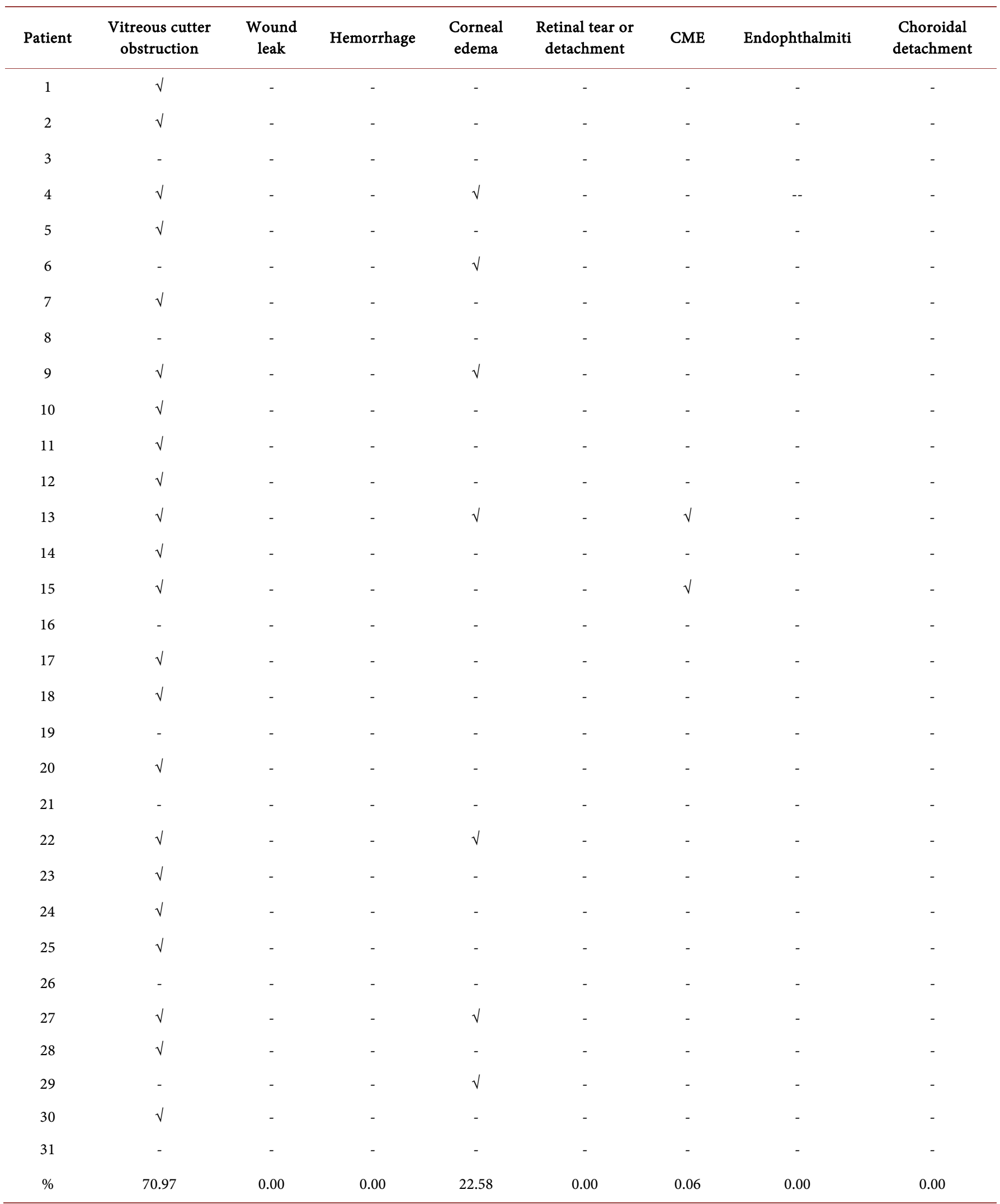


treated. A rapid resolution to normal pressure occurred within 24 hours. No long-term medication was needed to control the postoperative intraocular pressure.

No patient exhibited an IOP below $5 \mathrm{mmHg}$. No endophthalmitis or choroidal detachments were observed during the follow-up (Table 3 ).

\section{Discussion}

This report demonstrated the utility of a 23-gauge PPV system alone combined with our bimanual technique for the removal of particular dense posteriorly dislocated crystalline lenses.

The occurrence of a posteriorly dislocated crystalline lens following complicated cataract surgery is a well-documented complication of modern cataract surgeries that occurs in approximately $0.3 \%$ to $1.1 \%$ of all cases [1].

The removal of posteriorly dislocated crystalline lenses from the vitreous cavity and subsequent visual recovery has been successfully achieved with 20-gauge PPV systems for many years. However, the diameter of 20 -gauge devices is $0.9 \mathrm{~mm}$, which may necessitate relatively large corneal incisions. Complications of 20-gauge PPV procedures, including retinal detachment, $\mathrm{CME}$, hypotonia, and glaucoma, have been reported by many authors [2] [3].

Over the past decade, micro-incision vitrectomy surgeries using either 23- or 25gauge systems have increased in popularity among surgeons [4]-[11]. The advantages of small-incision PPV over the traditional 20-gauge approach include a reduction in surgical trauma, self-sealing wounds, decreased post-operative inflammation and faster visual recovery [12] [13].

However, cases with particular dense lens material are still a challenge for the smaller 23- or 25-gauge systems. One sclerotomy is commonly enlarged by the majority of surgeons to allow for the use of a 20-gauge fragmatome. Kiss and Vavvas [5] reported a small series of 6 patients who were treated with 25-gauge PPV for dislocated lens fragments and found that this minimally invasive approach was unable to remove dropped nuclear material in $50 \%$ of cases; in these cases, the completion of fragment removal required a 20-gauge phacofragmatome. Barthelmes et al. [11] combined the 23-gauge PPV system with an intravitreal fragmatome to remove dense retained nuclei.

However, it has been hypothesized that intravitreal fragmatome use increases the risk of retinal break formation and worsens outcomes [4].

Based on our clinical experiences, we found it hard to cut the particular dense lens material by the vitreous cutter alone without bimanual cooperation. When the lens material was extremely hard, it was difficult to be suctioned into the vitreous cutter without help. At the meantime, if the lens material was too big for the cutter to grasp, it was also difficult to be guided into the cutter, only when it was disassembled into smaller pieces. Thus, the bimanual technique we described utilized the 23-gauge cutter as a phaco tip to aspirate the lens material and utilized the light pipe as a prechopper to aid the cutting of the lens fragments into smaller pieces. We also followed the basic ideas and surgical techniques of traditional cataract surgery, using both the "stop-and- 
chop" and "divide-and-conquer" techniques.

This bimanual cooperation avoided the need to open the conjunctiva and enlarge a sclerotomy, the risk of thermal damage to the sclerotomy sites during fragmentation and the potential problem of inflow/outflow mismatch associated with the larger-bore fragmatomes combined with small-gauge infusion lines.

In 22 cases (73.33\%), dense nuclear pieces obstructed the vitreous cutter, but these obstructions were easily removed via the manual injection of a balanced salt solution into the cutter.

Postoperative complications were rare and involved no occurrences of retinal detachment, hypotonia, endophthalmitis and choroidal detachment. Only 2 patients (6.67\%) developed postoperative CME, and 1 patient (3.33\%) exhibited a postoperative IOP greater than $30 \mathrm{mmHg}$ on the first postoperative day.

Therefore, this report demonstrated that patients with particular dense lens material could achieve good outcomes when managed with the optimization of the cutter duty cycle, a strong vacuum and a low cut rate combined with our bimanual technique.

\section{Conclusion}

This study was as far the first clinical trial using such bimanual technique for the removal of particular dense posteriorly dislocated crystalline lenses. Our bimanual technique was proved to be an effective and safe method for those particular dense lenses using 23-gauge alone without the help of intravitreal fragmatome. Apart from the obvious strength of smaller incisions and fewer complications, it is extremely meaningful for those medical institutions where intravitreal fragmatome facilities are out of hand. However, it has several limitations as follows: small sample size, criteria for surgical procedures, and surgeon-dependent techniques. Further studies with large sample size conducted with various surgeons are needed.

\section{References}

[1] Kageyama, T., Ayaki, M., Ogasawara, M., et al. (2001) Results of Vitrectomy Performed at the Time of Phacoemulsification Complicated by Intravitreal Lens Fragments. British Journal of Ophthalmology, 85, 1038-1040. https:/doi.org/10.1136/bjo.85.9.1038

[2] Kwok, A.K., Li, K.K., Lai, T.Y., et al. (2002) Pars Plana Vitrectomy in the Management of Retained Intravitreal Lens Fragments after Cataract Surgery. Clinical \& Experimental Ophthalmology, 20, 399-403. https:/doi.org/10.1046/j.1442-9071.2002.00568.x

[3] Merani, R., Hunyor, A.P., Playfair, T.J., et al. (2007) Pars Plana Vitrectomy for the Management of Retained Lens Material after Cataract Surgery. American Journal of Ophthalmology, 144, 364-370. https:/doi.org/10.1016/j.ajo.2007.05.027

[4] Fujii, G.Y., De Juan Jr., E., Humayun, M.S., et al. (2002) A New 25-Gauge Instrument System for Transconjunctival Sutureless Vitrectomy Surgery. Ophthalmology, 109, 1807-1812. https:/doi.org/10.1016/S0161-6420(02)01179-X

[5] Eckardt, C. (2005) Transconjunctival Sutureless 23-Gauge Vitrectomy. Retina, 25, 208-211. https:/doi.org/10.1097/00006982-200502000-00015

[6] Kiss, S. and Vavvas, D. (2008) 25-Gauge Transconjunctival Sutureless Pars Plana Vitrecto- 
my for the Removal of Retained Lens Fragments and Intraocular Foreign Bodies. Retina, 28, 1346-1351. https:/doi.org/10.1097/IAE.0b013e318180ab7a

[7] Ho, L.Y., Walsh, M.K. and Hassan, T.S. (2010) 25-Gauge Pars Plana Vitrectomy for Retained Lens Fragments. Retina, 30, 843-849. https:/doi.org/10.1097/IAE.0b013e3181cd47d5

[8] Baker, P.S., Spirn, M.J., Chiang, A., et al. (2011) 23-Gauge Transconjunctival Pars Plana Vitrectomy for Removal of Retained Lens Fragments. American Journal of Ophthalmology, 152, 624-627. https:/doi.org/10.1016/j.ajo.2011.04.003

[9] Cho, M. and Chan, R.P. (2011) 23-Gauge Pars Plana Vitrectomy for Management of Posteriorly Dislocated Crystalline Lens. Clinical Ophthalmology, 5, 1737-1743. https:/doi.org/10.2147/OPTH.S22331

[10] Horozoglu, F., Yanyali, A., Macin, A., et al. (2012) 23-Gauge Transconjunctival Sutureless Vitrectomy for Retained Lens Fragments after Complicated Cataract Surgery. Retina, 32, 493-498. https:/doi.org/10.1097/IAE.0b013e3182252b13

[11] Barthelmes, D., Alexander, S., Mitchell, P., et al. (2012) Hybrid 20/23-Gauge Pars Plana Vitrectomy for Retained Lens Fragments after Cataract Surgery. Retina, 32, 1749-1755. https:/doi.org/10.1097/IAE.0b013e3182453309

[12] Park, D.H., Shin, J.P. and Kim, S.Y. (2009) Surgically Induced Astigmatism in Combined Phacoemulsification and Vitrectomy; 23-Gauge Transconjunctival Sutureless Vitrectomy versus 20-Gauge Standard Vitrectomy. Graefés Archive for Clinical and Experimental Ophthalmology, 247, 1331-1337. https:/doi.org/10.1007/s00417-009-1109-3

[13] Yanyali, A., Horozoglu, F., Macin, A., et al. (2011) Corneal Topographic Changes after Transconjunctival 23-Gauge Sutureless Vitrectomy. International Ophthalmology, 31, 277 282. https:/doi.org/10.1007/s10792-011-9453-9

Submit or recommend next manuscript to SCIRP and we will provide best service for you:

Accepting pre-submission inquiries through Email, Facebook, LinkedIn, Twitter, etc. A wide selection of journals (inclusive of 9 subjects, more than 200 journals)

Providing 24-hour high-quality service

User-friendly online submission system

Fair and swift peer-review system

Efficient typesetting and proofreading procedure

Display of the result of downloads and visits, as well as the number of cited articles Maximum dissemination of your research work

Submit your manuscript at: http://papersubmission.scirp.org/

Or contact ojoph@scirp.org 